\title{
Entrevista com Christian Ullmann
}

\section{Interview with Christian Ullmann}

\author{
Mariana Piccoli ${ }^{[1]}$, Alexandre Vergínio Assunção ${ }^{[2]}$
}

\begin{abstract}
Christian Ullmann é formado em Diseño Industrial pela Facultad de Arquitectura, Diseño y Urbanismo de la Universidad de Buenos Aires - Argentina. Designer porteño, makerpredigital, reside no Brasil desde 1996, consultor em design, inovação e gestão para a criação e desenvolvimento de produtos, projetos, sistemas e serviços. Coordenador de projetos para empresas, governos e instituições no Brasil e Latinoamérica, seus produtos e projetos e mobiliários receberam prêmios na Itália, Espanha, Brasil e Argentina. Professor e palestrante de Pensamento Projetualem diferentes instituições de Ensino nacionais e internacionais. Sócio do escritório de consultoria e design especializado em desenvolvimento de projetos e produtos com responsabilidade social e ambiental. Participou do Progetto Biologico Centro Studi Alessi, 1995 na Itália e Grécia. Coordenou o Projeto de Divulgação de Madeiras Amazônicas LPF/IBAMA, 1999. Criador e curador da Mostra Design \& Natureza, Shopping D\&D, 1999 a 2009. Participou da criação e coordenação do NIDA/SP - Núcleo de Inovação e Design em Artesanato do Estado de São Paulo (Via Design - SEBRAE SP - CSPD). Curador do setor Design para Melho-

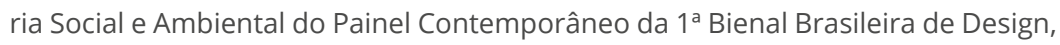
2006. pesquisador do Núcleo de Design \& Sustentabilidade da UFPR. Membro fundador da Rede Latinoamericana de Design Sustentável, Red Alebrije. coordenador de Design do Projeto Como Penso Como, 2013. coordenador Núcleo Exploratório de Design do Istituto Europeu di Designdesde 2015-2018. Coordenador de projetos do Centro de Inovação do Istituto Europeu di Design.
\end{abstract}

[1] Doutorado em Ciência e Engenharia de Materiais (em andamento), UFPEL.marianap.piccoli@gmail.com

[2] Doutorado em Educação, UFPEL. alex.ifsul@gmail.com 


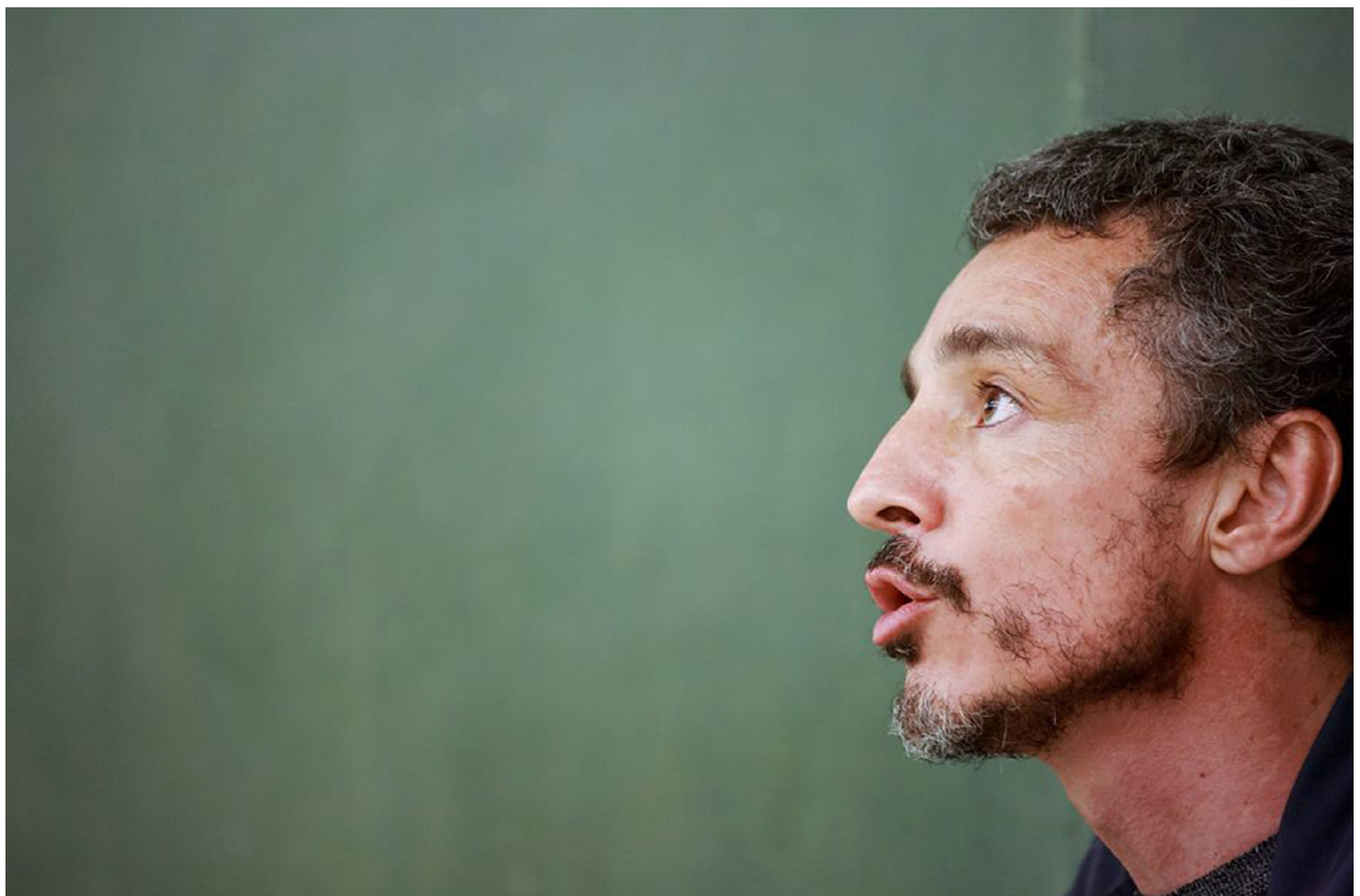

Figura 01: Christian Ullmann. Fonte: Gabriel Rodrigues

\section{Para iniciar, você poderia fazer uma breve apresentação de sua trajetória e experiências no Design, contando um pouco sua biografia?}

Sou formado em Diseño Industrial pela Facultad de Arquitectura, Diseño y Urbanismo de La Universidad de Buenos Aires (UBA) - Argentina. Em outubro de 1995 participei da $1^{\text {a }}$ Semana do Design do Mercosul organizado pelo LBDI[3], em Florianópolis, e em fevereiro de 1996 estava trabalhando no Programa de Melhoria do Móvel do Distrito Federal no Instituto de Ciência e Tecnologia - DF, com uma bolsa do CNPq. Um dos vizinhos e parceiros do Programa era o IBAMA e eles estavam desenvolvendo o projeto de divulgação de madeira alternativa da Amazônia para a fabricação de móveis. Fiquei curioso, me envolvi e aqui se iniciou meu aprendizado e jornada pela valorização dos recursos naturais, pelas técnicas e tecnologias apropriadas e pelos aspectos culturais locais. Aos poucos e

[3] Laboratório Brasileiro de Design (LBDI) - projeto em parceria com o Conselho Nacional de Pesquisa e Desenvolvimento (CNPq), a Financiadora de Estudos e Pesquisa (FINEP), a Universidade Federal do Estado de Santa Catarina (UFSC) e a Federação das Indústrias do Estado de Santa Catarina (FIESC), que viria a ser sediado na cidade de Florianópolis (SC). 
errando muito entendi que design é isso - aqui umas das primeiras descobertas: de que o desenho industrial é uma coisa; design, outra totalmente diferente.

No ano 2000 vim para São Paulo, onde abri um escritório de consultoria de design junto com a designer Tania de Paula. Hoje posso dizer que trabalhamos em um escritório voltado para projetos exploratórios e culturais dentro da ampla ideia do design, é isso que nos motiva a fazermos melhor. Também em São Paulo iniciei minhas atividades como docente. Sempre gostei de estar em sala de aula, lembro que no meu primeiro ano de estudante universitário tinha um ou dois professores que ficavam conosco falando da vida e fazendo as conexões com design, isto também está em mim. Gosto de trocar ideias com os jovens curiosos e movidos por mudar o mundo. Dá um pouquinho de saudades dessa época. Ensino é um rito, uma passagem. Se alguém fez isso [ensinar] muito bem com você, você pode gostar. Cada um tenta passar isso para a próxima geração.

\section{Como surgiu seu interesse por projetos socialmente responsáveis e pela sustentabilidade?}

Esta é uma curiosidade desde a época de aluno. Eu me perguntava: como as etnias primitivas conseguiam resolver tudo com os recursos disponíveis (faziam suas casas com tronco e folha de palmeiras e no final do uso os próprios materiais se reintegram a natureza) e nós com um sem fim de artefatos não conseguimos. Em contraposição, nossas moradias - passados mais de 5000 anos de "evolução" - não conseguem o mesmo.

Aqui surgem minhas perguntas e dúvidas: evoluímos para onde? Nesta ocasião é importante fazer referência ao contexto social e aos professores, amigos, que foram meus professores e inspiradores para "projetar no design"; e aqui repito as palavras de um deles, o professor Caio Vassão, pesquisador de Metadesign, que conheci, há uns cinco anos, aqui em São Paulo. Abordagem interessante e importante se o que 
você gosta de fazer não se encaixa no modelo convencional do design de mercado - talvez a minha maior característica.

Em 1995 tive a oportunidade de visitar por primeira vez a cidade de Milão (Itália) e participar do Progetto Biologico do Centro Studi Alessi: estava na Meca do design, trabalhando para a empresa mais significativa da sua época. Porém, um ano depois estava conhecendo e me envolvendo com as diferentes realidades amazônicas e isto me pareceu mais significativo. A imperfeição e instabilidade das oportunidades amazônicas (design) me pareceram mais interessantes e desafiadoras que as certezas e perfeição do mundo "Alessi" (design industrial). Por óbvio, isto não estava claro para mim, talvez agora com mais de vinte anos de experiência eu consiga construir esta reflexão.

\section{Quais as principais dificuldades, em sua opinião, para que sejam desenvolvidos e fabricados produtos mais sustentáveis?}

Bom, aqui temos muitos pontos de vistas e opiniões contraditórias: posso argumentar a partir do mercado, dos empresários, dos consumidores, dos designers, das ONGs e dos recursos disponíveis. Porém, aqui e agora, gostaria de falar a partir de outro ponto de vista, e falar que nós não sabemos o que significa fazer um produto "sustentável", pois o desenho industrial nunca teve isto como objetivo e talvez nunca vá ter.

A tecnologia e o ecossistema "industrial" do século XX só funcionam consumindo muita energia, muito recurso material e necessitam de muitos recursos humanos. $O$ norteador dentro do mundo capitalista é o dinheiro, e quanto mais fica na mão do empreendedor, melhor. Isto é a qualquer custo. Os recursos sociais, ambientais, culturais, de gênero, governança, etc., não formavam parte da equação; tentar agora incluí-los no modelo estabelecido está sendo um exercício interessante, porém não estamos vendo grandes resultados.

Sim, conseguimos fazer produtos mais sustentáveis em relação ao modelo anterior do mesmo produto ou do pro- 
duto concorrente; porém isto é um paliativo e apenas uma etapa na transição para uma nova economia e um novo ecossistema produtivo, que estão sendo gerados.

Para realmente termos produtos sustentáveis, necessitamos discutir, pensar, pesquisar, projetar, produzir, usar, de forma diferente. Já falamos de "ecodesign", depois de "design para a sustentabilidade", estamos falando de "design centrado no usuário" e, proximamente, vamos falar de "design circular" dentro de um novo modelo da "economia circular". E realmente é o melhor que podemos fazer hoje? Claro, a pergunta é: o que é, e o que significa fazer "design circular"?

Sim, é a evolução, o conceito de "design industrial" entra em "cheque" e cada vez é mais aceito o conceito de "design", amplo, difuso, customizado - o século XXI não tem mais respostas prontas, todas as perguntas têm de ser feitas de novo e de formas diferentes para descobrir novos caminhos e pensar diferente; criar diferente e usar diferente.

Por exemplo: depois do Tsunami no Japão e os problemas com a usina nuclear de Fukushima, a Alemanha entendeu que, apesar de ser uma geração de energia rentável (custo/benefício), era de alto risco e em poucos anos decidiu fechar as usinas nucleares apostando em energia renovável.

Hoje, pelo mundo, existem bairros, cidades inteiras com telhados de células fotovoltaicas que, conseqüentemente, mudaram o modelo de geração e distribuição de energia: de modelo centralizado do século dezenove/vinte para um modelo distribuído, onde todos os usuários podem ser geradores.

Isto é design, sempre foi, e, tomara, sempre seja.. A pergunta é: qual é o problema? Se a resposta é energia e segurança, pronto - vamos pensar em modelos mais seguros e lá na frente veremos como faremos isso funcionar, viabilizando economicamente. 


\section{De que forma inserir as questões de sustentabilidade no processo de projeto?}

Bom, se seguirmos a linha de pensamento da pergunta anterior, não tem como inserir nada onde as coisas não cabem. Então vamos testar essa ideia de "pensar diferente", "perguntar diferente", e a pergunta ficaria assim: Como, a partir do design, do processo de projeto, podemos trabalhar com as questões de sustentabilidade?

Façam esse exercício, pois é muito bom e vocês vão descobrir que as respostas não são produtos, as respostas não são processos produtivos industriais, concentrados em pólos produtivos globais; as respostas têm que ser muito diferentes do que conhecemos, pois o que conhecemos nos trouxe até aqui. A proposta vai ter que ser muito diferente do que conhecemos e sabemos fazer. Criem seu cenário ideal "sustentável" e depois, aos poucos, achem as conexões e ou disrupções necessárias para fazerem a passagem do real e atual para o ideal.

Outro bom momento de projetos "mais sustentáveis" no Brasil foi o período de proximidade com o Núcleo de Design Sustentável da UFPR, coordenado pelo prof. Aguinaldo Santos, onde aconteceram perguntas diferentes, olhando para a sociedade, e a partir das quais surgem sistemas, produtos, serviços e novas alternativas.

Por outro lado, sempre estive perto do universo da moda. Minha mãe é costureira. Ela fazia roupa para mim. Sempre vi os recortes de tecidos novos sendo jogados no lixo (sobras de modelagem). Agora, se entendemos que estes 10 a $20 \%$ de tecido novo têm um alto custo de recursos naturais, energéticos e humanos e entendemos que estes são importantes, deveríamos propor uma modelagem diferente. Hoje isto é conhecido como moda zero waste, mais um exercício para todo estudante e jovem profissional da área de design: pensar e projetar sem gerar descarte e resíduo. A natureza faz isso há mais de quatro bilhões de anos e não conseguimos aprender isso direito ainda. A natureza não joga nada fora, aliás, não 
tem como jogar fora. Fora de que? Fora de onde? O máximo que conseguimos é jogar longe, o mais longe possível...

Atualmente, você nota uma mudança no pensamento e na consciência dos designers, em relação ao desenvolvimento de projetos mais sustentáveis? Como você enxerga o futuro do design focado para a sustentabilidade?

Sim, design para a sustentabilidade é importante e pode ser foco para estudantes e jovens profissionais inseridos no universo corporativo e de políticas industriais para os nossos países. Se compararmos com dez anos atrás, estamos muito melhores. Hoje toda escola de design tem uma disciplina de "Design e Sustentabilidade" e os jovens profissionais já saem com este diferencial das escolas para o mercado.

Porém o futuro do design é fazer "metadesign" e projetar sua forma de pensar, e projetar o futuro de design é fazer "design", com o que tudo isso significa. Não dá para fazer um smartphone que utilize recursos naturais de áreas de conflito, com uma vida curta, pois sua degradação contamina o solo. Do plástico utilizado só conseguimos reciclar $10 \%$ e o resto vai para um aterro sanitário ou oceanos mundo afora. Mas, mais uma vez a pergunta é: qual é o problema?

Recentemente, no Encuentro Latinoamericano de Design (Buenos Aires) discutiu-se sobre a incessante busca pela identidade do design nacional. Tendo se graduado em Design Industrial na Argentina e residir e trabalhar no Brasil, que identidade você enxerga no design sul-americano? Há alguma característica que una o design desses países?

Estes encontros Latinos são muito bons, pois acontecem levando em conta diferentes realidades e pontos de vista. Gosto muito disto. Bom, nasci na Argentina, em particular na cidade de Buenos Aires, capital do país. Estudei Design na capital enturmado com o melhor que a Argentina tinha. Na universidade nunca desenvolvemos um projeto para co- 
nhecer e tentar resolver algum problema endêmico nacional. Nada real e nada significativo em relação ao nosso contexto e recorte nacional. Nossos olhares, como estudantes e profissionais, sempre estiveram fora, nas capitais européias. 0 primeiro mundo sempre foi a nossa referência, para professores, profissionais e alunos. Hoje é diferente. Porém, desde que cheguei ao Brasil, em 1996, entendi que meu universo é da Patagônia até Amazônia. E, é aí onde eu posso dar o meIhor de mim. Gosto dessa geografia, gosto desse clima, gosto do povo que vive nestas terras, me identifico, estou em casa, tenho sangue tupi guarani, pelo menos $1 \%$.

A identidade é um conjunto de características únicas que se aprende e se constrói dia a dia, portanto eu vejo identidade, sim. Para fazer esta afirmação é necessário criar recortes e recortes de recortes. Os designers que tem suas cabeças, ideias e projetos propostos para o público europeu - fazem isso, sim - estão aqui na América do Sul, porém querem estar na Europa. Eu estou falando de designers que estão por aqui (em qualquer cidade deste lado do mundo) e pensam a partir daqui, para as pessoas daqui, com as características daqui, a partir das limitações tecnológicas locais. E, claro, quando analisamos estes produtos com a lente de "bom design", da escola de Ulm, nos sentimos cachorros vira-latas. Eu gosto de cachorros vira-latas e isto nos faz sermos os melhores designers do mundo: com dois pregos enferrujados e um arame deixamos uma cadeira em pé. Essa forma de pensar, de construir nosso pensamento projetual, nos diferencia da Europa. Tomara que nunca percamos esta característica.

Há pouco tempo corrigi meu curriculum, tirei a palavra "Argentino" e coloquei "Portenho". Um país é um território grande ou muito grande, como aqui no Brasil, e cada um de nós não consegue ter as características multiculturais, multidiversificadas do país. Por enquanto acredito que tenho muitas características da cidade de Buenos Aires onde nasci, estudei, convivi, estudei design, trabalhei um pouco e depois, no Brasil, entendi que fortalecer estas características era 
bom para mim. Nas ultimas décadas os países estão perdendo força para cidades, e seguramente esta lenta mudança vai continuar. A FIFA esta pensando uma Copa do Mundo de Times de Futebol, e é claro, hoje o Barcelona tem tantos ou mais torcedores que o país Brasil. O Time de Barcelona, a Seleção do Barcelona ou time similar é melhor que a de muitos Selecionados Nacionais de primeira linha. Quando escolhi o Brasil, casei com uma brasileira e tivemos um filho de dupla nacionalidade. Entendi que as coisas estão mudando, aliás, a mudança é continua. O mais difícil é estar no tempo certo e que este tempo seja representativo para cada um de nós.

Quando era estudante de Design na argentina, chegou a tecnologia do email e justo nessa época os europeus falavam de nós, sul-americanos, como "sudacas" uma palavra inventada e pejorativa. Quando entendi isso, pensei: eu sou sudaca e eu quero ser o melhor sudaca possível. E meu primeiro email foi: resudaca@hotmail.com. Aqui necessitamos de mais explicações: em Buenos Aires é muito comum incluir o prefixo RE para alguma coisa ou ação muito boa. Ex. uma comida rica (gostosa) seria uma comida "rerica". Então eu não sou "sudaca", eu sou "resudaca". E hoje meu email pessoal é: resudaca@gmail.com. Claro, aqui as contradições, resudaca@ hotmail ou gmail, como assim? Pode ser um resudaca, globalizado, conectado com os sistemas tecnológicos dominantes. Ninguém é perfeito...

Você já expôs trabalhos em diferentes feiras, no Brasil e no exterior, e recentemente lançou o livro "Brasil Faz Design: criatividade brasileira no cenário internacional", junto com Marili Brandão e Sandra Nedopetalski. Qual sua percepção sobre como o design brasileiro é visto? Qual é o principal diferencial do design feito aqui?

Gosto do design brasileiro, me identifico. O design brasileiro é uma atividade projetual inserida num contexto sócio-bio-cultural-político, muito bem definido e diferente ao resto do mundo; a isto devemos acrescentar o "tempo" que estamos 
vivendo, e dá nisso que vemos nas lojas, revistas, nas feiras, nos livros. E se consideramos todas estas variáveis é possível ver algumas características do povo brasileiro também: multicultural, diversificado, multimaterial, colorido, bem-humorado - que tem desde alta tecnologia a sem tecnologia nenhuma. Quando apresentamos por primeira vez uma coleção de móveis de designers brasileiros utilizando madeiras da floresta amazônica, certificados pelo selo FSC no Fuori Salone, durante a Feira Internacional do Móvel de Milão, em 2000, dentro do Prêmio "Brasil Faz Design", com a Marili Brandão, vimos europeus não acreditarem nas cores das madeiras, admirarem os projetos, quererem sentar em todas as cadeiras - seguramente, se fosse hoje, teríamos as maiores relevâncias das redes com likes, selfies e comentários.

Mais uma vez o design feito aqui tem que ter recorte universal, processos produtivos, mercado, interesses. Este seria um bom tema para mestrado: selecionar produtos projetados e produzidos no Brasil e realizar avaliações comparativas para entender mais e melhor o que somos e como somos. Depois poderíamos fazer isso com colombianos, mexicanos e argentinos e assim teríamos realmente olhares sul-americanos para avaliações sul-americanas para produtos sul-americanos.

O Prof. Marcos Braga, historiador do Design, fala em toda aula de abertura: o design só faz sentido se ele é contextualizado, pois assim se pode entender o que está acontecendo ou aconteceu nesse período da história.

Quando criamos nossa tabela de valores e a validamos, voltamos a falar deste assunto. Bom, pelo menos assim faria um europeu - e aqui caímos de novo na armadilha do design: é difícil se livrar do pensamento projetual europeu, isso sempre atrapalha para ser realmente o que somos ou queremos ser.

Seria muito bom querer ser e se aceitar: vira-lata, cafona e mestiço - claro, isto visto a partir da lente de "bom design", que na minha livre tradução ao "sulamericanês", significa: liberdade, alegria, leveza e viver um dia depois do outro. 


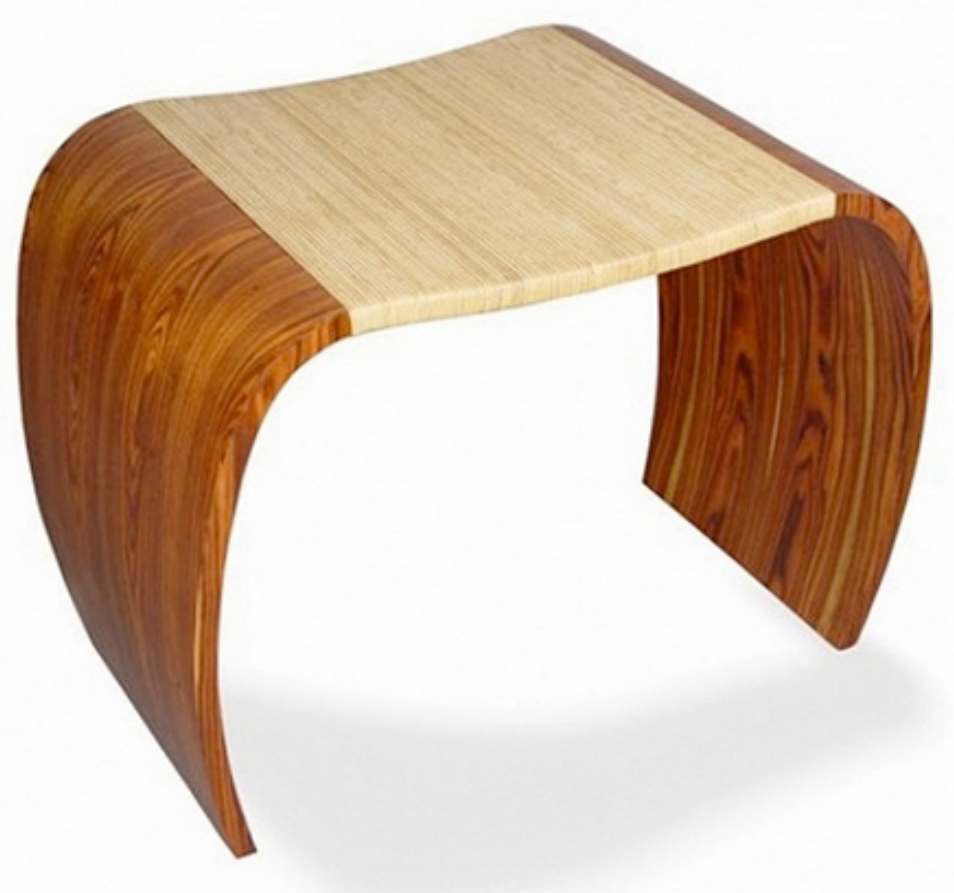

Figura 02: Banco "Taui", projetado por Christian Ullmann. Fonte: acervo do entrevistado.

Apesar de a necessidade do objeto ser produzido em massa, industrialmente, não ser mais requisito imprescindível para descrever a área do Design, você ainda enxerga nas universidades de design uma resistência ao objeto de produção artesanal?

Sim, é difícil tirar de nós o que funcionou muito bem durante 50 anos e nos ensinou a ser o que somos hoje. Quando tiramos o adjetivo "industrial" do design, abrimos infinitas portas e não só o artesanal. Desde o ano 2000 que comprei essa briga com as escolas de design; porém hoje essa não deveria ser nossa maior preocupação: industrial ou artesanal, mais uma vez a pergunta é maior. Hoje temos design físico, virtual, tangível, intangível; e cada um deles tem suas subdivisões.

Por exemplo, o design físico pode ser: industrial, semi industrial, semi artesanal, artesanal, virtual, realidade aumentada, pode ser uma peça única, um lote definido, uma produ- 
ção seriada, uma produção massiva. E podemos fazer uma produção massiva com mão de obra intensiva, com máquinas industriais, com robôs e agora também com impressoras 3D.

Sim a partir do ano 2000 tudo expandiu, era bem mais fácil quando falávamos de "design industrial", agora que falamos de "design" temos que entender cada vez mais do que estamos falando e o que estamos fazendo. Esta é a realidade do nosso tempo complexo - para quem ainda não leu, sugiro ler "Design para um Mundo Complexo", do Rafael Cardoso.

\section{Desde sua formação em Design Industrial, em 1992, até sua atual carreira como docente no IED São Paulo (Istituto Europeo de Design), que mudanças você vê no ensino de Design?}

Aconteceram muitas mudanças e seguramente a maior foi a tecnológica: na década de 80 ainda usávamos régua T e prancheta; hoje ninguém sai do computador. Se compararmos com a possibilidade de acesso a referências para desenvolver projetos, quando era aluno só tinha umas poucas revistas que chegavam de 3 a 6 meses atrasadas na Argentina. Hoje todo aluno de design está sabendo em tempo real o que está acontecendo no lançamento de uma empresa em uma feira, e se conectamos uns óculos VR (virtual reality, realidade virtual) conseguimos estar em qualquer lugar do mundo.

No que refere a ensino é difícil fazer mudanças radicais nos programas de ensino e nas matrizes dos cursos, as mudanças acontecem de forma incremental. Aos pouco acontecem, de forma programada e metodológica e de outros jeitos, pois professores inconformados e irreverentes apresentam novas possibilidades para os alunos, e dando certo, as mudanças são incorporadas.

Claro que isto tem que ser assim, tem que acontecer, estamos falando de Design e não de Direito. Porém este não é um problema só do Brasil ou da América do Sul. Se procurarmos escolas de design de vanguarda podemos contar com os dedos de uma mão. Mudanças também nos incomodam, 
nos tiram do chão, e não estamos prontos a toda hora para entender e aceitar mudanças.

\section{Finalizando, você poderia deixar uma mensagem (ou um conselho) aos designers e estudantes da área?}

A partir da experiência acumulada como estudante de design, 7 anos (sim, não fui uns dos melhores estudantes da minha turma) e 28 anos de profissional, sei que faria tudo de novo.

Hoje seria muito bom começar de novo, o futuro que está nas mãos de vocês é de dar inveja. As limitações do design da década de 80 e 90 não existem mais. Hoje falamos de intangíveis, realidade aumentada, inovação social, erro como parte de processo.

Quando era estudante de primeiro ano tive uma aula Magna de abertura de semestre com o Tomas Maldonado (argentino, pintor, filósofo, professor e diretor da escola de UIm) e ele falou para todos nós de coisas que não entendíamos, que não formavam parte do nosso contexto, e no momento não entendi nada; porém nunca consegui esquecer do que ele falou: geladeiras. Ele comentava que uma geladeira tinha que ter mais de uma porta, e eu e todos ficamos olhando como ele estava falando de absurdos e coisas desconectadas com a realidade industrial local, e distante da compreensão das pessoas. Tomas estava falando de consumo de energia, no início da era do ecodesign, e como reduzir o consumo de energia das geladeiras no projeto: com diferentes portas e elas menores se comparadas com a grande porta única de uma geladeira. Cada vez que abríssemos uma das portas menores, a perda de frio seria menor e por consequência o consumo de energia seria menor também.

Agora estou aqui, falando absurdos para estudantes e jovens profissionais da área de design. Pode ser que seja um pouco de arrogância também, porém a experiência de mais de 30 anos só pensando design serviram muito bem para mim e alguma coisa pode ajudar mais alguém. 


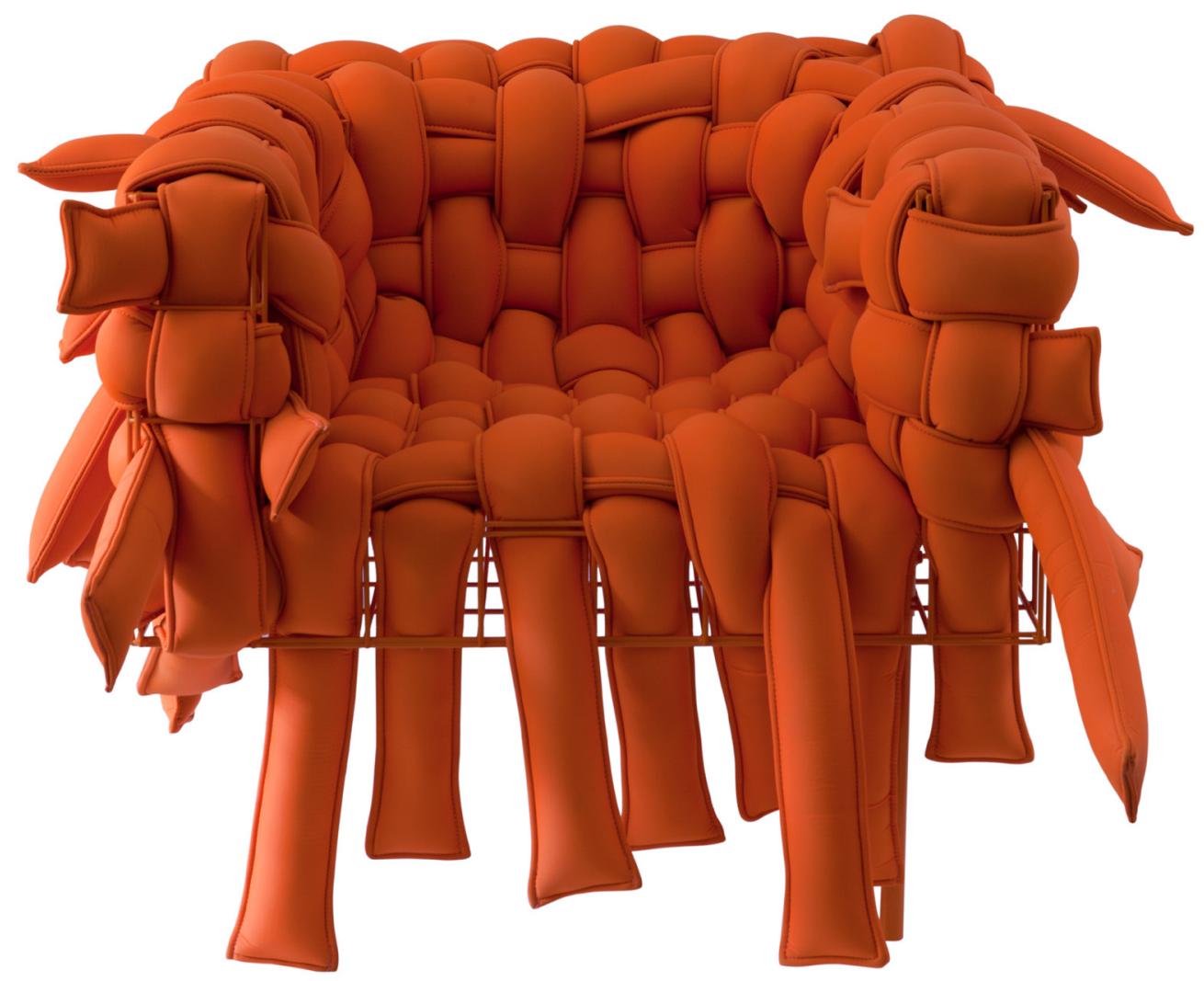

Figura 03: Poltrona "Underconstruction", projetada por Christian Ullmann. Fonte: acervo do entrevistado.

Está na hora de inverter o olhar - sempre olhamos para a Europa, sempre olhamos para o melhor do melhor; talvez esteja na hora de olhar para a periferia, e a partir desta realidade construir alternativas e soluções para uma melhor qualidade de vida para as pessoas que ali moram.

Aqui estamos falando mais de mobilidade, moradia, saneamento, educação, empreendedorismo, desenvolvimento e produção local, cultivo agroflorestal (não podemos esquecer que estamos no Brasil, um país tropical!), fornecimento de água limpa, entre outros, e menos de sofás para capa de revista, roupas para a produção do ano ou apps que nos façam virar unicórnios. 
Não é fácil nadar contra a corrente, mas no final do dia faz um bem maior. Aos poucos, se todos entendermos que isto é o importante, vão ser as revistas que vão nos procurar para sermos os melhores do ano.

Tenho inveja dos músicos. E no Brasil mais ainda, dos músicos e poetas sambistas e da lá para cá, todo os ritmos tem esta característica. Eles conseguem pegar o espírito do tempo, acrescentar a melodia, e nós simples mortais cantarolamos para o resto da vida. Eles (ao contrário de nós, designers) olham de baixo para cima, de dentro para fora, estão conectados com seu contexto e a partir dali que surpreendem o mundo inteiro.

E para terminar, um último comentário: este ano tive a oportunidade de participar do lançamento do livro: “Design, quando todos fazem design" do teórico Italiano Ezio Manzini. Estávamos em Caruaru (município de Pernambuco) e durante um passeio terminamos em um pequeno centro cultural, onde poetas locais estavam fazendo músicas de MPB e ele comentou o mesmo. Falou: "é isso, [o design] tem que ser como as músicas populares mais famosas. Todos tem que saber, tem que entender, tem que decorar, tem que cantar".

Trabalhem para isso, serem os melhores, o melhor que cada um de vocês pode ser, nos surpreendam, se surpreendam. Testem mil e uma vezes, até acreditarem ter a melhor versão possível de algo.

\section{Para saber mais}

https://www.behance.net/christianullmann

https://christianullmann.wordpress.com/ 